\title{
Penerapan Metode Branch and Bound dalam Optimalisasi Produk Mebel (Studi kasus: Toko Mebel di Jalan Marsan Panam)
}

\author{
Elfira Safitri ${ }^{1 a)}$, Sri Basriati ${ }^{1 b)}$ dan Hasyratul Najmi ${ }^{1 c)}$ \\ ${ }^{1}$ Program Studi Matematika, Fakultas Sains dan Teknologi, Universitas Islam Negeri Sultan Syarif Kasim Riau \\ a) email: elfira.safitri@uin-suska.ac.id \\ b) email: sribasriati@uin-suska.ac.id \\ c)email: hasyratulnajmi96@gmail.com
}

\begin{abstract}
Abstrak
Setiap pelaku usaha atau pelaku ekonomi pasti melakukan prinsip ekonomi yaitu dengan usaha atau modal yang sedikit mampu menghasilkan keuntungan yang banyak, sehingga menyebabkan munculnya masalah optimasi yaitu memaksimumkan keuntungan agar mendapatkan hasil yang optimal. Metode yang digunakan dalam penelitian ini adalah metode Branch and Bound. Penelitian ini bertujuan untuk mengetahui optimalisasi produk mebel yang berada di jalan Marsan Panam menggunakan metode Branch and Bound. Solusi awal didapat menggunakan metode simpleks. Apabila hasilnya bernilai non integer maka dilanjutkan dengan metode Branch and Bound untuk mendapatkan solusi yang integer. Berdasarkan hasil penelitian diperoleh bahwa untuk mengoptimalkan produk mebel dengan keuntungan maksimal, maka toko mebel di Jalan Marsan Panam menerima pesanan produk mebel tempat tidur sebanyak 4 unit, lemari tiga pintu sebanyak 4 unit, lemari dua pintu sebanyak 2 unit dan meja makan sebanyak 3 unit dengan keuntungan produksi sebesar Rp. 14.250.000.
\end{abstract}

Kata kunci: Branch and bound, integer, metode simpleks, optimasi

\begin{abstract}
Every actor in business or economic actor must carry out the principle of economy with a little effort or capital capable of gaining a lot of profits, therefore causing the emergence of optimization linear programming problems that is maximized profits in order to get optimal result. The method used in this study is the Branch and Bound method. This study aims to determine the optimization of furniture products on the street Marsan Panam using the Branch and Bound method. The initial solution is obtained using the simplex method. If the result is non-integer then it can be followed by the Branch and Bound method to get an integer solution. Based on the results of this study, the writer found out that in optimizing furniture production to gain maximum profit, then the furniture shop on the street Marsan Panam received orders for 4 bed type furnitre products, 4 units of three-door cabinet, 2 units of two-door cabinet and 3 units of dining table with manufacturing profit Rp. 14,250,000.
\end{abstract}

Keywords: Branch and bound, integer, simplex method, optimization.

e-ISSN: 2686-0341 p-ISSN: 2338-0896 


\section{Pendahuluan}

Sumber daya merupakan input dalam setiap proses produksi, namun secara tidak langsung telah terjadi pemborosan yang dilakukan oleh perusahaan terutama usaha kecil dan menengah [7]. Setiap pelaku usaha atau pelaku ekonomi pasti melakukan prinsip ekonomi yaitu dengan usaha atau modal yang sedikit mampu menghasilkan keuntungan yang banyak, sehingga menyebabkan munculnya masalah optimasi. Masalah optimasi meliputi memininumkan biaya atau memaksimumkan keuntungan dengan kapasitas sumber daya yang ada agar mampu mendapatkan hasil yang optimal [8]. Untuk mendapatkan penyelesaian optimal dari masalah tersebut dikembangkan suatu cara yang disebut dengan program linier (linear programming). Program linier adalah suatu teknik penyelesaian optimal atas suatu masalah keputusan dengan cara menentukan terlebih dahulu fungsi tujuan (memaksimumkan atau meminimumkan) dari kendala-kendala yang ada dalam persamaan linier. Program linier sering digunakan dalam menyelesaikan masalah alokasi sumber daya [10].

Suatu permasalahan program linier menginginkan nilai variabel keputusannya berupa integer, agar jawaban persoalan menjadi realistik. Integer Linear programming merupakan suatu model program linier yang khusus digunakan untuk menyesuaikan suatu masalah dimana nilai variabel-variabel keputusan dalam penyelesaian optimal haruslah merupakan bilangan integer (bilangan bulat). Integer Linear Programming dapat diselesaikan dengan banyak cara, antara lain dengan menggunakan grafik, eliminasi, subtitusi dan lain-lain. Salah satu cara yang cukup efektif untuk menyelesaikan program integer adalah dengan mengaplikasikan algoritma Branch and Bound dibandingkan metode perhitungan nilai bulat lainnya dan telah menjadi kode komputer standar untuk Integer Linear Programming [1].

Metode Branch and Bound ini sudah banyak dilakukan oleh peneliti-peneliti sebelumnya diantaranya penelitian yang dilakukan Pagiling, dkk [6] yang berjudul "Optimalisasi Hasil Produksi Tahu dan Tempe Menggunakan Metode Branch and Bound (Studi Kasus: Pabrik Tempe Eri Jl.Teratai No.04 Palu Selatan)", Suryawan,dkk [11] yang berjudul "Penerapan Branch and Bound Algorithm dalam Optimalisasi Produksi Roti". kemudian penelitian Hikmah dan Nusyafitri [4] yang berjudul Aplikasi Integer Linear Programming untuk Meminimumkan Biaya Produksi pada Siaputo Aluminium, dan Nurjanah [5] yang berjudul Metode Branch and Bound untuk Meminimalkan Biaya Bahan Baku.

Berdasarkan rujukan penelitian di atas penulis tertarik untuk melanjutkan penelitian yang dilakukan oleh Nurjanah [5] menggunakan kasus produk mebel di Jalan Marsan Panam dengan fungsi tujuan adalah memaksimumkan keuntungan. Adapun tujuan dari penelitian ini adalah untuk mengetahui kombinasi jumlah produk mebel yang akan diproduksi untuk mengoptimalkan keuntungan menggunakan metode Branch and Bound.

\section{Metode}

Metode Simpleks

Metode simpleks merupakan salah satu teknik penyelesaian dalam program linier yang digunakan sebagai teknik pengambilan keputusan dalam permasalahan yang berhubungan dengan pengalokasian sumber daya secara optimal. Metode simpleks digunakan untuk mencari nilai optimal dari program linier yang melibatkan banyak constraint (pembatas) dan banyak variabel (lebih dari dua variabel) [2].

Adapun Langkah - langkah metode simpleks sebagai berikut:

a. Mengubah fungsi tujuan dan fungsi kendala kedalam bentuk standar. 
b. Menyusun persamaan - persamaan kedalam bentuk tabel awal simpleks.

c. Menentukan entering variable.

d. Menentukan leaving variable.

e. Melakukan operasi baris elementer untuk membuat koefisien entering variable pada baris dengan rasio positif terkecil berharga 1 dan berharga 0 pada baris-baris lainnya.

f. Solusi dikatakan optimal untuk kasus maksimasi apabila pada baris $z$ sudah bernilai positif atau nol dan untuk kasus minimasi sudah negatif atau nol, maka solusi optimal telah diperoleh. [2]

Integer Linear Programming (ILP)

Pemrograman Integer (Integer Linear Programming) adalah pemrograman linier dengan variabel berupa bilangan bulat atau integer [12].

Bentuk umum dari Integer Programming adalah:

Maks/Min

$$
Z=\sum_{j=1}^{n} c_{j} x_{j}
$$

kendala

$$
\begin{aligned}
& \sum_{j=1}^{n} a_{i j} x_{j}(\leq /=/ \geq) b_{i}, \text { untuk } i=1,2,3, \ldots, m \\
& x_{j} \geq \mathrm{O}, \text { untuk } j=1,2,3, \ldots, n \\
& x_{j} \text { bernilai integer untuk semua } j
\end{aligned}
$$

\section{Metode Branch and Bound}

Metode Branch and Bound merupakan salah satu metode untuk menghasilkan penyelesaian optimal program linier yang menghasilkan variabel-variabel keputusan bilangan bulat. Sesuai dengan namanya, metode ini membatasi penyelesaian optimum yang akan menghasilkan bilangan pecahan dengan cara membuat cabang atas dan bawah bagi masing-masing variabel keputusan yang bernilai pecahan agar bernilai bilangan bulat sehingga setiap pembatasan akan menghasilkan cabang baru [3].

Langkah-langkah dalam metode Branch and Bound yaitu:

a. Menyelesaikan model Program Linier menggunakan metode simpleks.

b. Memeriksa solusi optimal, jika variabel basis yang diharapkan bernilai integer, maka solusi optimal telah tercapai. Tetapi jika tidak bernilai integer maka lanjutkan Langkah c.

c. Memilih variabel yang mempunyai selisih pecahan terbesar dengan bilangan bulat dari masingmasing variabel untuk dijadikan percabangan kedalam sub-masalah.

d. Membuat batasan baru $X_{j}{ }^{*} \leq X_{j} \leq X_{j}{ }^{*}+1$, tetapi karena range tersebut tidak memberikan pemrograman integer, maka konsekuensinya nilai integer $X_{j}$ memenuhi salah satu syarat yaitu: $X_{j}^{*} \leq X_{j}$ dan $X_{j} \geq X_{j}^{*}+1$.

e. Menyelesaikan model program linear dengan batasan baru yang ditambahkan pada setiap submasalah. Jika solusi yang diharapkan benilai integer, maka kembali ke Langkah 4. Tetapi jika tidak bernilai integer maka kembali ke Langkah 3.

f. Jika solusi dari salah satu sub-masalah tersebut telah bernilai integer dan solusi lainnya tidak memiliki penyelesaian (tidak fisibel), maka percabangan tidak dilanjutkan atau berhenti. 
g. Memilih solusi optimal. Jika ada beberapa sub-masalah yang memiliki solusi bernilai integer, maka dipilih solusi yang memiliki nilai $z$ terbesar jika fungsi tujuan adalah maksimum dan dipilih solusi yang memiliki $z$ terkecil jika fungsi tujuan adalah minimum untuk dijadikan solusi optimal [9]. Bentuk flowchart metode Branch and Bound yang dapat dilihat pada Gambar 1 berikut:

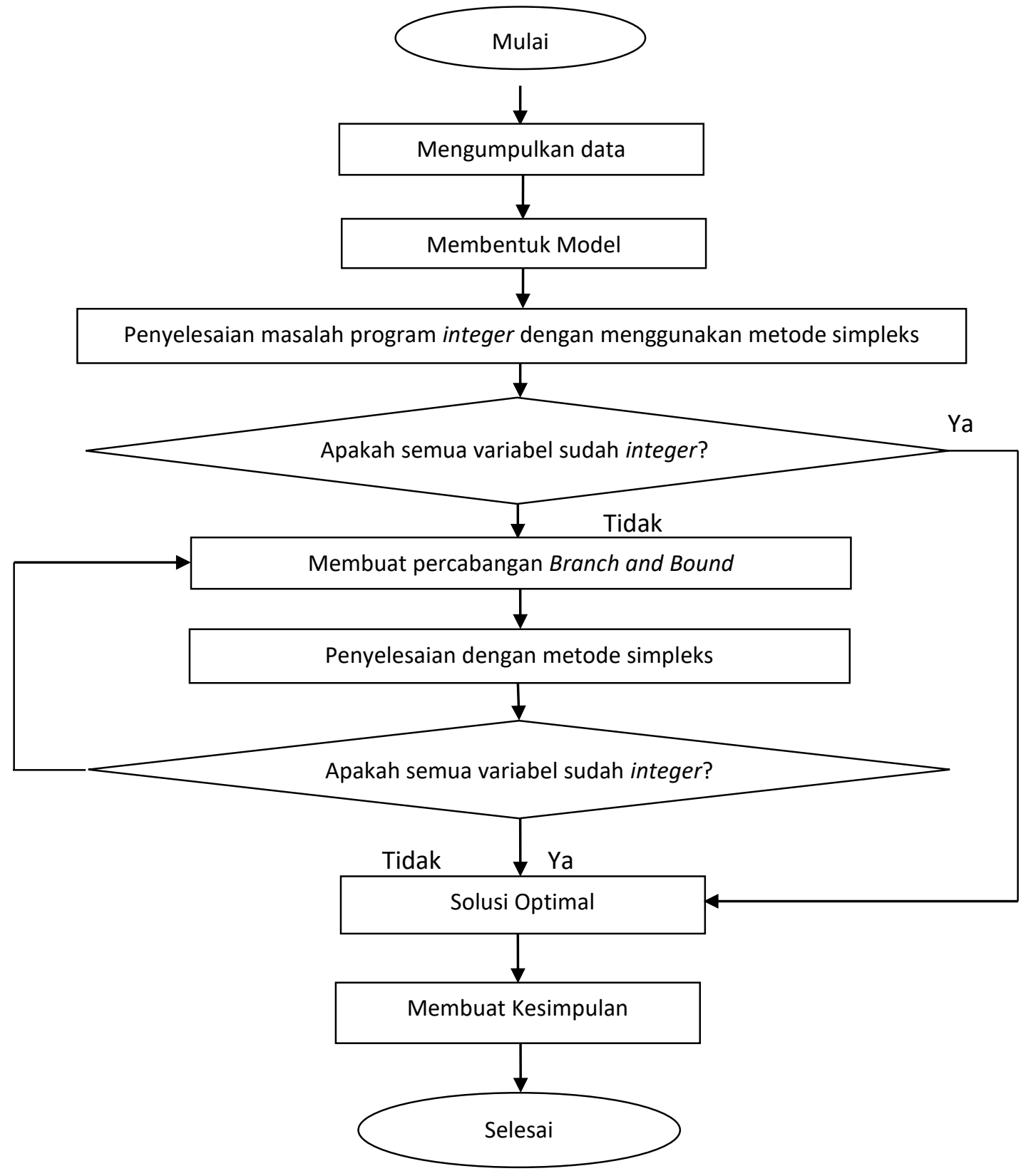

Gambar 1. Flowchart Metode Branch and Bound 


\section{Hasil dan Diskusi}

Penelitian ini berisikan pembahasan mengenai proses optimalisasi produk mebel di Jalan Marsan, Panam dengan menggunakan metode Branch and Bound. Fungsi tujuan dari permasalahan toko mebel yang berada di jalan marsan panam dapat dilihat pada Tabel 1 berikut:

Tabel 1. Keuntungan Penjualan Produk Mebel

\begin{tabular}{llc}
\hline NO & \multicolumn{1}{c}{ Jenis Produk Mebel } & $\begin{array}{c}\text { Keuntungan } \\
\text { (Rupiah) }\end{array}$ \\
\hline 1 & Tempat Tidur & 1.200 .000 \\
2 & Lemari tiga pintu & 1.200 .000 \\
3 & Lemari dua pintu & 750.000 \\
4 & Sofa & 600.000 \\
5 & Kursi Tamu & 300.000 \\
6 & Meja Makan & 1.050 .000 \\
7 & Bofet tv & 450.000 \\
8 & Meja Rias & 300.000 \\
9 & Pelaminan & 3.000 .000 \\
\hline
\end{tabular}

Fungsi kendala untuk permasalahan produk mebel yang berada di Jalan Marsan, Panam dapat dilihat dari bahan - bahan finishing pembuatan masing - masing jenis produk mebel yang terdapat pada Tabel 2 berikut:

Tabel 2. Bahan-Bahan dalam Finishing Pembuatan Jenis Produk Mebel

\begin{tabular}{|c|c|c|c|c|c|c|c|c|c|c|}
\hline \multirow{2}{*}{$\begin{array}{c}\text { Bahan-bahan } \\
\text { Finishing }\end{array}$} & \multicolumn{9}{|c|}{ Jenis Produk Mebel } & \multirow[b]{2}{*}{ Stok } \\
\hline & $x_{1}$ & $x_{2}$ & $x_{3}$ & $x_{4}$ & $x_{5}$ & $x_{6}$ & $x_{7}$ & $x_{8}$ & $x_{9}$ & \\
\hline $\begin{array}{l}\text { Melamin } \\
\text { Clear (L) }\end{array}$ & 0,5 & 0,5 & 0,3 & 0,5 & 1 & 2 & 1 & 1 & 5 & $25(\mathrm{~L})$ \\
\hline Sanding (L) & 1 & 1 & 0,75 & 1 & 1 & 2 & 0,5 & 0,5 & 3 & $25(\mathrm{~L})$ \\
\hline Amplas (m) & 2 & 2 & 1,25 & 2 & 1,75 & 2 & 1,5 & 2 & 8 & $25(\mathrm{~m})$ \\
\hline Dempul (kg) & 0,5 & 0,5 & 0,5 & 0,5 & 0,5 & 0,5 & 0,3 & 0,25 & 1 & $10(\mathrm{~kg})$ \\
\hline Pewarna Shelaac (L) & 0,5 & 0,5 & 0,5 & 0,5 & 0,5 & 0,25 & 0,25 & 0,3 & 0,5 & $10(L)$ \\
\hline Tinner (L) & 5 & 5 & 4 & 3 & 5 & 5 & 4 & 3 & 10 & $100(\mathrm{~L})$ \\
\hline
\end{tabular}

Toko produk mebel di Jalan Marsan, Panam telah memesan rata-rata masing-masing produk mebel dari Jawa yang dapat dilihat pada Tabel 3 berikut:

Tabel 3. Data Jumlah Pesan Produk Mentah

\begin{tabular}{cc}
\hline Produk Mentah & Persediaan \\
\hline Tempat tidur & 4 unit \\
Lemari 3 pintu & 4 unit \\
Lemari 2 pintu & 2 unit \\
\hline
\end{tabular}




\begin{tabular}{cc}
\hline Produk Mentah & Persediaan \\
\hline Sofa & 5 unit \\
Kursi tamu & 6 unit \\
Meja makan & 3 unit \\
Bofet tv & 2 unit \\
Meja rias & 4 unit \\
Pelaminan & 1 unit \\
\hline
\end{tabular}

\section{Keterangan:}

$x_{1}$ : Jumlah produk tempat tidur yang dipesan.

$x_{2}$ : Jumlah produk lemari 3 pintu yang dipesan.

$x_{3}$ : Jumlah produk lemari 2 pintu yang dipesan

$x_{4}$ : Jumlah produk sofa yang dipesan.

$x_{5}$ : Jumlah produk kursi tamu yang dipesan.

$x_{6}$ : Jumlah produk meja makan yang dipesan.

$x_{7}$ : Jumlah produk bofet tv yang dipesan.

$x_{8}$ : Jumlah produk meja rias yang dipesan.

$x_{9}$ : Jumlah produk pelaminan yang dipesan.

\section{a. Penyelesaian menggunakan Metode Simpleks}

Berdasarkan Data pada Tabel 1, Tabel 2 dan Tabel 3 di atas, maka dapat dibentuk dalam model program linier yaitu sebagai berikut:

Maksimumkan

$$
\begin{aligned}
z= & 1.200 .000 x_{1}+1.200 .000 x_{2}+750.000 x_{3}+600.000 x_{4}+300.000 x_{5} \\
& +1.050 .000 x_{6}+450.000 x_{7}+300.000 x_{8}+3.000 .000 x_{9}+0 S_{1}+0 S_{2} \\
& +0 S_{4}+0 S_{5}+0 S_{6}+0 S_{7}+0 S_{8}+0 S_{9}+0 S_{10}+0 S_{11}+0 S_{12}+0 S_{13}+0 S_{14}+0 S_{15}
\end{aligned}
$$

Kendala

$$
\begin{aligned}
& 0,5 x_{1}+0,5 x_{2}+0,3 x_{3}+0,5 x_{4}+x_{5}+2 x_{6}+x_{7}+x_{8}+5 x_{9}+S_{1}=25 \\
& x_{1}+x_{2}+0,75 x_{3}+x_{4}+x_{5}+2 x_{6}+0,5 x_{7}+0,5 x_{8}+3 x_{9}+S_{2}=25 \\
& 2 x_{1}+2 x_{2}+1,25 x_{3}+2 x_{4}+1,75 x_{5}+2 x_{6}+1.5 x_{7}+2 x_{8}+8 x_{9}+S_{3}=25 \\
& 0,5 x_{1}+0,5 x_{2}+0,5 x_{3}+0,5 x_{4}+10,5 x_{5}+0,5 x_{6}+0,3 x_{7}+0,25 x_{8}+x_{9}+{ }_{4}=10 \\
& 0,5 x_{1}+0,5 x_{2}+0,5 x_{3}+0,5 x_{4}+0,5 x_{5}+0,25 x_{6}+0,25 x_{7}+0,3 x_{8}+0,5 x_{9}+S_{5}=10 \\
& 5 x_{1}+5 x_{2}+4 x_{3}+3 x_{4}+5 x_{5}+5 x_{6}+4 x_{7}+3 x_{8}+10 x_{9}+S_{6}=100 \\
& x_{1}+S_{7}=4 ; x_{2}+S_{8}=4 ; x_{3}+S_{9}=2 ; x_{4}+S_{10}=5 ; x_{5}+S_{11}=6 ; x_{6}+S_{12}=3 ; \\
& x_{7}+S_{13}=2 ; x_{8}+S_{14}=2 ; x_{9}+S_{15}=1 . \\
& x_{1}, x_{2}, x_{3}, x_{4}, x_{5}, x_{6}, x_{7}, x_{8}, x_{9}, S_{1}, S_{2}, S_{3}, S_{4}, S_{5}, S_{6}, S_{7} S_{8}, S_{9}, S_{10}, S_{11}, S_{12}, S_{13}, S_{14}, S_{15} \geq 0
\end{aligned}
$$

Setelah dikonversikan ke dalam bentuk standar, selanjutnya akan ditentukan variabel basis dan variabel non-basis. Untuk metode simpleks yang menjadi variabel basis adalah $S_{1}, S_{2}, S_{3}, S_{4}, S_{5}, S_{6}, S_{7} S_{8}, S_{9}, S_{10}, S_{11}, S_{12}, S_{13}, S_{14}, S_{15}$. Sedangkan yang menjadi variabel non-basis adalah semua variabel mulai dari variabel keputusan dan variabel slack. Setelah ditentukan variabel basis dan non-basis, elemen-elemen dari Persamaan (3) dimasukkan ke dalam tabel awal simpleks yang dapat dilihat pada Tabel 4 berikut: 
Tabel 4. Tabel Awal Simpleks

\begin{tabular}{|c|c|c|c|c|c|c|c|c|c|c|c|c|c|c|c|c|c|c|c|c|c|c|c|c|c|}
\hline VB & $x_{1}$ & $x_{2}$ & $x_{3}$ & $x_{4}$ & $x_{5}$ & $x_{6}$ & $x_{7}$ & $x_{8}$ & $x_{9}$ & $S_{1}$ & $S_{2}$ & $S_{3}$ & $S_{4}$ & $S_{5}$ & $S_{6}$ & $S_{7}$ & $S_{8}$ & $S_{9}$ & $S_{10}$ & $S_{11}$ & $S_{12}$ & $S_{13}$ & $S_{14}$ & $S_{15}$ & NK \\
\hline$z$ & -1200 & -1200 & -750 & -600 & -300 & -1050 & -450 & -300 & -3000 & 0 & 0 & 0 & 0 & 0 & 0 & 0 & 0 & 0 & 0 & 0 & 0 & 0 & 0 & 0 & 0 \\
\hline$S_{1}$ & 0,5 & 0,5 & 0,3 & 0,5 & 1 & 2 & 1 & 1 & 5 & 1 & 0 & 0 & 0 & 0 & 0 & 0 & 0 & 0 & 0 & 0 & 0 & 0 & 0 & 0 & 25 \\
\hline$S_{2}$ & 1 & 1 & 0,75 & 1 & 1 & 2 & 0,5 & 0,5 & 3 & 0 & 1 & 0 & 0 & 0 & 0 & 0 & 0 & 0 & 0 & 0 & 0 & 0 & 0 & 0 & 25 \\
\hline$S_{3}$ & 2 & 2 & 1,25 & 2 & 1,75 & 2 & 1,5 & 2 & 8 & 0 & 0 & 1 & 0 & 0 & 0 & 0 & 0 & 0 & 0 & 0 & 0 & 0 & 0 & 0 & 25 \\
\hline$S_{4}$ & 0,5 & 0,5 & 0,5 & 0,5 & 0,5 & 0,5 & 0,3 & 0,25 & 1 & 0 & 0 & 0 & 1 & 0 & 0 & 0 & 0 & 0 & 0 & 0 & 0 & 0 & 0 & 0 & 10 \\
\hline$S_{5}$ & 0,5 & 0,5 & 0,5 & 0,5 & 0,5 & 0,25 & 0,25 & 0,3 & 0,5 & 0 & 0 & 0 & 0 & 1 & 0 & 0 & 0 & 0 & 0 & 0 & 0 & 0 & 0 & 0 & 10 \\
\hline$S_{6}$ & 5 & 5 & 4 & 3 & 5 & 5 & 4 & 3 & 10 & 0 & 0 & 0 & 0 & 0 & 1 & 0 & 0 & 0 & 0 & 0 & 0 & 0 & 0 & 0 & 100 \\
\hline$S_{7}$ & 1 & 0 & 0 & 0 & 0 & 0 & 0 & 0 & 0 & 0 & 0 & 0 & 0 & 0 & 0 & 1 & 0 & 0 & 0 & 0 & 0 & 0 & 0 & 0 & 4 \\
\hline$S_{8}$ & 0 & 1 & 0 & 0 & 0 & 0 & 0 & 0 & 0 & 0 & 0 & 0 & 0 & 0 & 0 & 0 & 1 & 0 & 0 & 0 & 0 & 0 & 0 & 0 & 4 \\
\hline$S_{9}$ & 0 & 0 & 1 & 0 & 0 & 0 & 0 & 0 & 0 & 0 & 0 & 0 & 0 & 0 & 0 & 0 & 0 & 1 & 0 & 0 & 0 & 0 & 0 & 0 & 2 \\
\hline$S_{11}$ & 0 & 0 & 0 & 0 & 1 & 0 & 0 & 0 & 0 & 0 & 0 & 0 & 0 & 0 & 0 & 0 & 0 & 0 & 0 & 1 & 0 & 0 & 0 & 0 & 6 \\
\hline$S_{12}$ & 0 & 0 & 0 & 0 & 0 & 1 & 0 & 0 & 0 & 0 & 0 & 0 & 0 & 0 & 0 & 0 & 0 & 0 & 0 & 0 & 1 & 0 & 0 & 0 & 3 \\
\hline$S_{13}$ & 0 & 0 & 0 & 0 & 0 & 0 & 1 & 0 & 0 & 0 & 0 & 0 & 0 & 0 & 0 & 0 & 0 & 0 & 0 & 0 & 0 & 1 & 0 & 0 & 2 \\
\hline$S_{14}$ & 0 & 0 & 0 & 0 & 0 & 0 & 0 & 1 & 0 & 0 & 0 & 0 & 0 & 0 & 0 & 0 & 0 & 0 & 0 & 0 & 0 & 0 & 1 & 0 & 4 \\
\hline$S_{15}$ & 0 & 0 & 0 & 0 & 0 & 0 & 0 & 0 & 1 & 0 & 0 & 0 & 0 & 0 & 0 & 0 & 0 & 0 & 0 & 0 & 0 & 0 & 0 & 1 & 1 \\
\hline
\end{tabular}

Setelah melakukan iterasi sebanyak 6 kali iterasi, maka diperoleh tabel optimum sebagai berikut: 
Tabel 5. Tabel Optimal Simpleks

\begin{tabular}{|c|c|c|c|c|c|c|c|c|c|c|c|c|c|c|c|c|c|c|c|c|c|c|c|c|c|}
\hline VB & $x_{1}$ & $x_{2}$ & $x_{3}$ & $x_{4}$ & $x_{5}$ & $x_{6}$ & $x_{7}$ & $x_{8}$ & $x_{9}$ & $S_{1}$ & $S_{2}$ & $S_{3}$ & $S_{4}$ & $S_{5}$ & $S_{6}$ & $S_{7}$ & $S_{8}$ & $S_{9}$ & $S_{10}$ & $S_{11}$ & $S_{12}$ & $S_{13}$ & $S_{14}$ & $S_{15}$ & NK \\
\hline$z$ & 0 & 0 & 0 & 150 & 356,3 & 0 & 112,5 & 450 & 0 & 0 & 0 & 1725 & 0 & 0 & 0 & 450 & 450 & $\begin{array}{l}281, \\
3\end{array}$ & 0 & 0 & 300 & 0 & 0 & 0 & $\begin{array}{l}14437, \\
5\end{array}$ \\
\hline$S_{1}$ & 0 & 0 & 0 & $-0,8$ & $-0,09$ & 0 & 0,06 & $-0,25$ & 0 & 1 & 0 & $-0,6$ & 0 & 0 & 0 & 0,8 & $-5,5$ & 0,48 & 0 & 0 & $-0,7$ & 0 & 0 & 0 & 14,09 \\
\hline$S_{2}$ & 0 & 0 & 0 & $-2,3$ & $-1,8$ & 0 & $-1,9$ & $-2,75$ & 0 & 0 & 1 & 0 & 0 & 0 & 0 & 2,3 & 2,3 & 0,5 & 0 & 0 & 1,25 & 0 & 0 & 0 & 19,13 \\
\hline$x_{6}$ & 0 & 0 & 0 & 0 & 0 & 1 & 0 & 0 & 0 & 0 & 0 & 1 & 0 & 0 & 0 & 0 & 0 & 0 & 0 & 0 & 1 & 0 & 0 & 0 & 3 \\
\hline$S_{4}$ & 0 & 0 & 0 & 0,25 & 0,28 & 0 & 0,11 & 0 & 0 & 0 & 0 & 0 & 1 & 0 & 0 & $-0,25$ & $-0,25$ & $-0,3$ & 0 & 0 & $-0,25$ & 0 & 0 & 0 & 3,43 \\
\hline$S_{5}$ & 0 & 0 & 0 & 0,38 & 0,39 & 0 & 0,16 & 0,8 & 0 & 0 & 0 & 0 & 0 & 1 & 0 & 0 & $-0,4$ & $-0,25$ & 0 & 0 & $-0,13$ & 0 & 0 & 0 & 4,53 \\
\hline$S_{6}$ & 0 & 0 & 0 & 0,5 & 2,8 & 0 & 2,12 & 0,5 & 0 & 0 & 0 & 0 & 0 & 0 & 1 & 0 & $-2,5$ & $-0,6$ & 0 & 0 & $-2,5$ & 0 & 0 & 0 & 40,12 \\
\hline$x_{1}$ & 1 & 0 & 0 & 0 & 0 & 0 & 0 & 0 & 0 & 0 & 0 & 0 & 0 & 0 & 0 & 1 & 0 & 0 & 0 & 0 & 0 & 0 & 0 & 0 & 4 \\
\hline$x_{2}$ & 0 & 1 & 0 & 0 & 0 & 0 & 0 & 0 & 0 & 0 & 0 & 0 & 0 & 0 & 0 & 0 & 1 & 0 & 0 & 0 & 0 & 0 & 0 & 0 & 4 \\
\hline$x_{3}$ & 0 & 0 & 1 & 0 & 0 & 0 & 0 & 0 & 0 & 0 & 0 & 0 & 0 & 0 & 0 & 0 & 0 & 1 & 0 & 0 & 0 & 0 & 0 & 0 & 2 \\
\hline$S_{10}$ & 0 & 0 & 0 & 1 & 0 & 0 & 0 & 0 & 0 & 0 & 0 & 0 & 0 & 0 & 0 & 0 & 0 & 0 & 1 & 0 & 0 & 0 & 0 & 0 & 5 \\
\hline$S_{11}$ & 0 & 0 & 0 & $-0,3$ & $-0,22$ & 0 & $-0,19$ & $-0,25$ & 0 & 0 & 0 & 0,13 & 0 & 0 & 0 & 0,25 & 0,25 & 0,16 & 0 & 1 & 0,25 & 0 & 0 & 0 & 0,94 \\
\hline$S_{12}$ & 0 & 0 & 0 & 0 & 0 & 0 & 0 & 0 & 0 & 0 & 0 & 0 & 0 & 0 & 0 & 0 & 0 & 0 & 0 & 0 & 0 & 0 & 0 & 0 & 2 \\
\hline$S_{13}$ & 0 & 0 & 0 & 0 & 0 & 0 & 1 & 0 & 0 & 0 & 0 & 0 & 0 & 0 & 0 & 0 & 0 & 0 & 0 & 0 & 0 & 1 & 0 & 0 & 4 \\
\hline$S_{14}$ & 0 & 0 & 0 & 0 & 0 & 0 & 0 & 1 & 0 & 0 & 0 & 0 & 0 & 0 & 0 & 0 & 0 & 0 & 0 & 0 & 0 & 0 & 1 & 0 & 0,06 \\
\hline$x_{9}$ & 0 & 0 & 0 & 0 & 0 & 0 & 0 & 0 & 1 & 0 & 0 & 0 & 0 & 0 & 0 & 0 & 0 & 0 & 0 & 0 & 0 & 0 & 0 & 0 & 0,0625 \\
\hline
\end{tabular}




\section{b. Penyelesaian Menggunakan Metode Branch and Bound}

Berdasarkan Tabel 5 di atas, diperoleh solusi optimal yaitu $x_{1}=4, x_{2}=4, x_{3}=2, x_{4}=0, x_{5}=0$, $x_{6}=3, x_{7}=0, x_{8}=0$ dan $x_{9}=0,0625$. karena yang belum integer hanya variabel $x_{9}$ maka $x_{9}=0,625$ menjadi variabel untuk percabangan yaitu subpersoalan 2 dengan menambahkan batas $x_{9} \leq 0$ dan subpersoalan 3 dengan menambahkan batas $x_{9} \geq 1$. Kemudian di cari solusi optimal dengan menggunakan metode simpleks, sehingga diperoleh solusi optimum dari tiap cabang. Proses percabangan ini di ulang sampai semua variabel bernilai integer. Setelah dilakukan percabangan sebanyak 5 percabangan atau 11 subpersoalan maka diperoleh solusi optimal sebagai berikut:

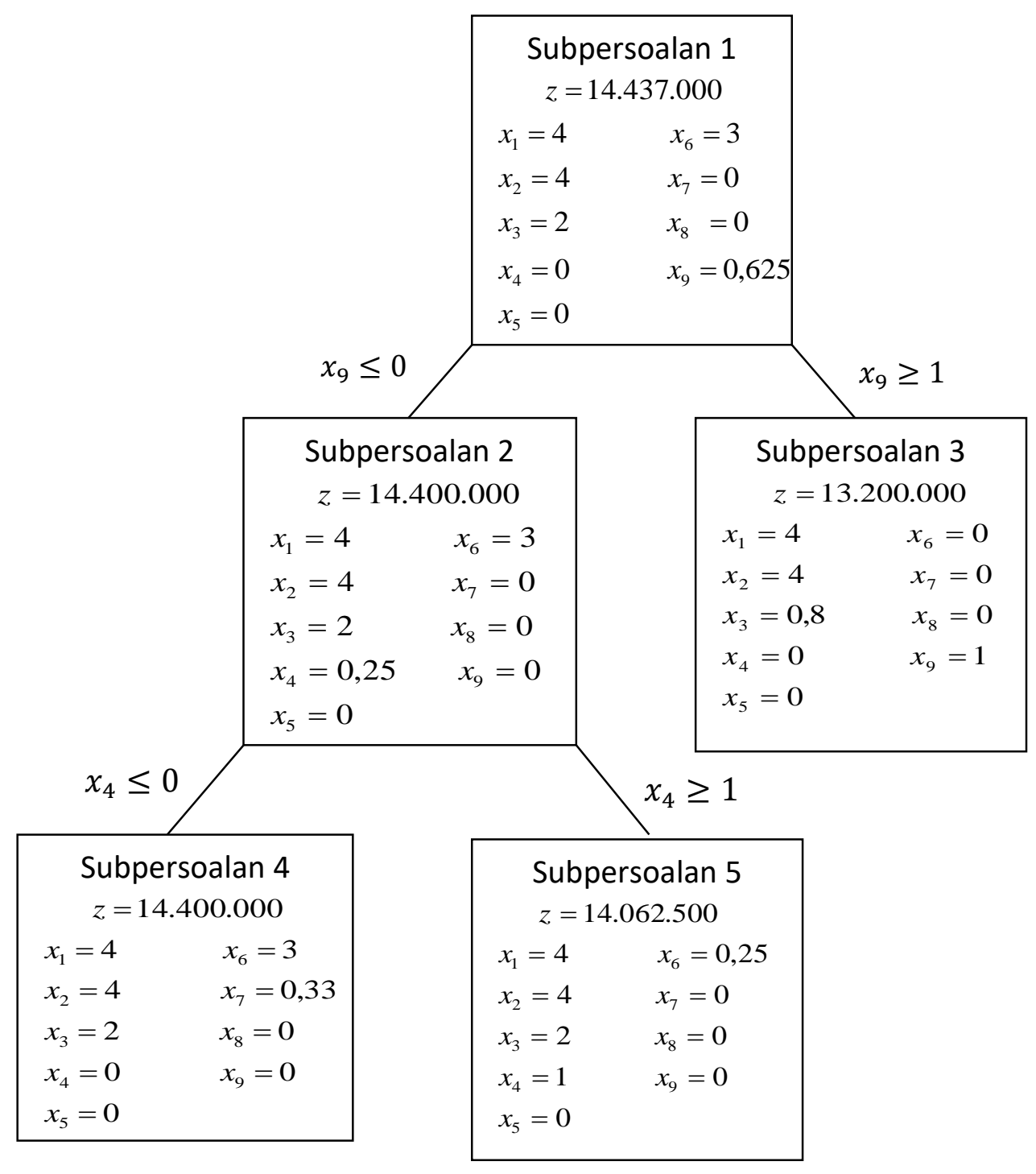




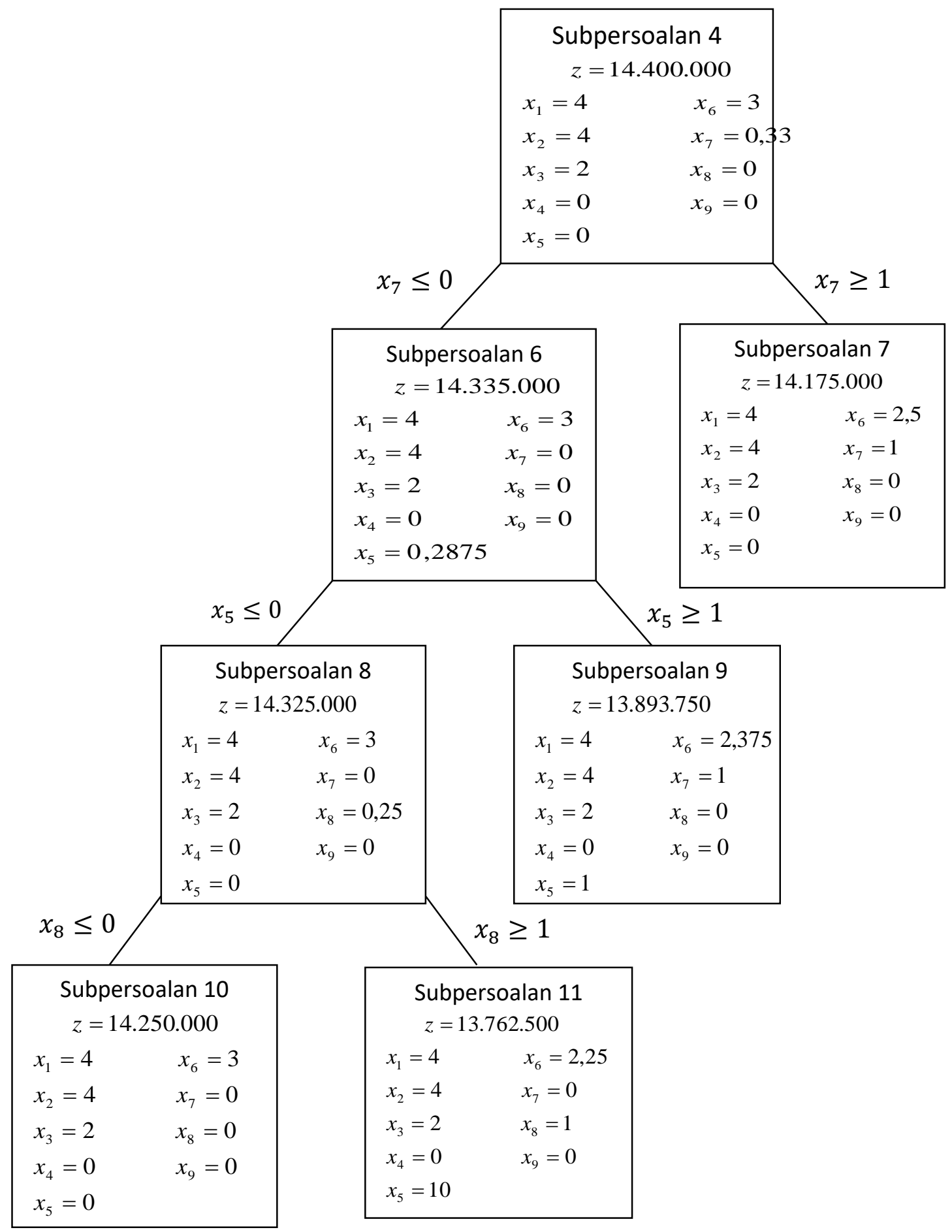

Gambar 2. Percabangan subpersoalan 10 dan subpersoalan 11

Berdasarkan Gambar 2 terlihat bahwa solusi optimum terbesar terdapat pada subpersoalan 10 untuk fungsi tujuan memaksimumkan keuntungan. Karena semua variabel pada subpersoalan 10 sudah 
bernilai integer, maka proses percabangan tidak dilanjutkan atau berhenti, sehingga diperoleh solusi optimal $z=14.250 .000, x_{1}=4, x_{2}=4, x_{3}=2, x_{4}=0, x_{5}=0, x_{6}=3, x_{7}=0, x_{8}=0$, dan $x_{9}=0$.

\section{Kesimpulan}

Berdasarkan pembahasan di atas, solusi optimal menggunakan metode branch and bound diperoleh $z=14.250 .000$ dengan $x_{1}=4, x_{2}=4, x_{3}=2, x_{4}=0, x_{5}=0, x_{6}=3, x_{7}=0, x_{8}=0$, dan $x_{9}=0$. Artinya mebel furniture di Jalan Marsan Panam memperoleh keuntungan produksi sebesar Rp. 14.250.000 dengan menerima pesanan produk mebel jenis tempat tidur sebanyak 4 unit, lemari 3 pintu sebanyak 4 unit, lemari 2 pintu sebanyak 2 unit dan meja makan sebanyak 3 unit dan mebel furniture di Jalan Marsan Panam tidak menerima pesanan untuk jenis produk sofa, kursi tamu, bofet tv, meja rias dan pelaminan.

\section{Ucapan Terima Kasih}

Penulis dapat mengucapkan terima kasih kepada pihak yang ikut berperan serta dalam penelitian ini, yang telah memberikan bantuan finansial dan atau fasilitas kepada penulis.

\section{Referensi}

[1] Aritonang, D.R.S. " Analisis Metode Branch and Bound dalam Mengoptimalkan Jumlah Produksi Roti". Skripsi. Universitas Sumatera Utara. 2013.

[2] Dimyati, Tjutju dan Dimyati A. "Operation Research: Model-Model Pengambilan Keputusan". Sinar Baru Bandung: Bandung. 2006.

[3] Hartono, Widi. "Implementasi Algoritma Branch and Bound pada 0-1 Knapsack

[4] Hikmah dan Nusyafitri, Amin. "Aplikasi Integer Programming untuk Meminimumkan Biaya Produksi pada Siaputo Aluminium". Jurnal Saintifik. Vol. 3, No. 2. 2017.

[5] Nurjannah. "Metode Branch and Bound untuk Meminimalkan Biaya Bahan Baku". Skripsi. Fakultas Sains dan Teknologi Universitas Islam Negeri Sultan Syarif Kasim Riau. 2018.

[6] Pagiling, Sahari, dan Rais. “Optimalisasi Hasil Produksi Tahu dan Tempe Menggunakan Metode Branch and Bound".Jurnal IImiah Matematika dan Terapan. Vol. 12, No.1 hal.53-63, 2015.

[7] Sauddin, Adnan, Kiki sumarni. "Integer Programming dengan Pendekatan Metode Branch and Cut Guna mengoptimalkan Jumlah Produk dengan Keuntungan Maksimal". Jurnal MSA. Vol. 3 No. 1, 2015.

[8] Septinauli, Dewi. "Aplikasi Metode Branch and Bound dan Cutting Plane untuk Mengoptimalkan Keuntungan Produksi Keripik Ubi pada UD. Rezeki Baru. Skripsi. Sarjana Fakultas Matematika dan Ilmu Pengetahuan Alam Universitas Sumatera Utara. 2019.

[9] Siswanto, "Operation Research". Jilid 1, Erlangga, Jakarta. 2007.

[10] Sitorus, Parlin. "Program Linier". Universitas Trisakti, Jakarta. 1997.

[11] Suryawan, Ni ketut taritastrawati, dan Kartika sari. "Penerapan Branch and Bound dalam Optimalisasi Produksi Roti". Jurnal Matematika . Vol. 4, hal. 148-155, 2016.

[12] Taha, H.A. "Riset Operasi (Edisi Revisi)”. Jakarta, Indonesia. 1996. 